\title{
Japanese Soybean Paste Miso Scavenges Free Radicals and Inhibits Lipid Peroxidation
}

\author{
Librado A. Santiago, Midori Hiramatsu,* and Akitane Mori \\ Department of Neurochemistry, Institute for Neurobiology, \\ Okayama University Medical School, \\ 2-5-1 Shikata-cho, Okayama 700, Japan \\ * Yamagata Technopolis Foundation, Yamagata 900, Japan
}

(Received November 18, 1991)

\begin{abstract}
Summary Japanese soybean paste miso, which has been reported to prevent gastric and mammary cancer and chronic nephritis, was demonstrated by electron spin resonance spectrometry using 5,5'-dimethyl-1 -pyrroline- $N$-oxide as a scavenger of free radicals. Fifty $\mathrm{mg} / \mathrm{ml}$ of miso scavenged $100 \%$ of 1,1 -diphenyl- 2 -picrylhydrazyl radicals $\left(3.9 \times 10^{15}\right.$ spins $/ \mathrm{ml}) ; 45 \mathrm{mg} / \mathrm{ml}$ quenched $92 \%$ of hydroxyl radicals $\left(7.9 \times 10^{16}\right.$ spins/ $\mathrm{ml})$; and $50 \mathrm{mg} / \mathrm{ml}$ quenched $50 \%$ of superoxide anion $\left(6.7 \times 10^{16}\right.$ spins/ $\mathrm{ml})$. In the system of rat cerebral cortex homogenate supplemented with $2 \mathrm{mM}$ each of $\mathrm{Fe}^{2+}$ and ascorbic acid, $90 \%$ and $82 \%$ of the hydrogen and carbon-centered radicals having $1.7 \times 10^{13} \mathrm{spins} / \mathrm{ml}$ and $3.9 \times 10^{13} \mathrm{spins} / \mathrm{ml}$, respectively, were quenched by $180 \mathrm{mg} / \mathrm{ml}$ of miso. The thiobarbituric acid-reactive substances, an index of lipid peroxidation in the brain, was inhibited by $10 \mathrm{mg} / \mathrm{ml}$ of miso. These results showed that miso acts as an antioxidant by scavenging free radicals.

Key Words soybean paste miso, antioxidant, free radicals, free radical scavenger, lipid peroxidation, electron spin resonance spectrometry
\end{abstract}

Antioxidative properties have been found in Oriental foods, specifically, soybean (1), and fermented soybean products such as natto (a traditional Japanese food) (2) and tempeh (a traditional Indonesian food) (3). Soybean paste or miso is another traditional product that is consumed in Asian countries as seasoning or pickling material. It is prepared by fermenting a mixture of steamed soybeans, wheat or malt, yeasts such as Saccharomyces cerevisiae and Pediococcus halophilus, salt and "koji" (a 48-h incubated mixture of steamed soybeans and fungi Aspergillus oryzae) (4). However, no information is available on the antioxidant activity or free radical scavenging action of miso.

By electron spin resonance (ESR) spectrometry, which is considered to be the least ambiguous method for the detection of free radicals (5), and using a spin trap 5,5'-dimethyl-1-pyrroline- $N$-oxide (DMPO), we examined the antioxidant/scave- 
nging action of miso on free radicals such as 1,1-diphenyl-2-picrylhydrazyl (DPPH), hydroxyl, superoxide, hydrogen and carbon-centered radicals. We analyzed also the thiobarbituric acid-reactive substances (TBARS) - a marker of lipid peroxidation-in rat cerebral cortex homogenate.

\section{METHODS}

Miso. A yellow variety of commercially available miso from Kaneko-miso Ltd. (Tokushima, Japan) was used.

Animals. Male adult Sprague-Dawley rats from CLEA Japan Inc. (Tokyo, Japan) weighing $240-260 \mathrm{~g}$ were housed for at least 1 week at $25^{\circ} \mathrm{C}$ and humidity of $50 \pm 5 \%$ and were allowed free access to water and a standard diet MF (Oriental Yeast, Tokyo, Japan). The rats were sacrificed by cervical decapitation. The cerebral cortex was immediately dissected on an ice plate and homogenized $(0.05 \%$ $\mathrm{w} / \mathrm{v}$ ) in $0.1 \mathrm{M}$ Tris/ $\mathrm{HCl}$ buffer, $\mathrm{pH} 7.4$.

Chemicals. Hypoxanthine, DPPH and diethylenetriaminepentaacetic acid (DETAPAC) were purchased from Sigma Chemical Co. (St. Louis, MO, USA); xanthine oxidase from Boehringer Mannheim GmbH (Germany); DMPO from Daiichi Pure Chemical Co. (Tokyo, Japan); vitamin C from Wako Pure Chemical Ind. Ltd. (Osaka, Japan); and vitamin E from Katayama Chemical (Osaka, Japan).

Radical analysis. The following free radicals were analyzed by ESR spectrometer (JEOL, JES-FE1XG, Tokyo, Japan).

DPPH: To $100 \mu \mathrm{l}$ of $30 \mu \mathrm{mol}$ of DPPH in ethanol was added $100 \mu \mathrm{l}$ of sample, which was then vortexed, placed in a special spectrometry flat cell (JEOL, Tokyo, Japan) and analyzed exactly after $60 \mathrm{~s}$.

Hydroxyl: Seventy-five microliters of $1 \mathrm{mM} \mathrm{FeSO}_{4}$ and $1 \mathrm{mM}$ DETAPAC, 75 $\mu 1$ of $1 \mathrm{M} \mathrm{H}_{2} \mathrm{O}_{2}, 50 \mu 1$ of sample (in water), and $20 \mu 1$ of $0.092 \mathrm{M}$ DMPO were vortexed and the DMPO-OH spin adducts were analyzed at $40 \mathrm{~s}$ after addition of DMPO.

Superoxide: Fifty microliters of $2 \mathrm{mM}$ hypoxanthine, $35 \mu 1$ of $11 \mathrm{mM}$ DETAPAC, $50 \mu 1$ of sample (in water), $15 \mu 1$ of DMPO, and $50 \mu 1$ of freshly prepared xanthine oxidase suspension $(81.6 \mu 1$ in $5 \mathrm{ml}$ of phosphate buffer, $\mathrm{pH} 7.8)$ were vortexed and the DMPO- $\mathrm{O}_{2}^{-}$spin adducts were analyzed at $50 \mathrm{~s}$ after addition of DMPO.

Hydrogen and carbon-centered radicals: To $0.5 \mathrm{ml}$ of rat cerebral cortex homogenate in Tris/ $\mathrm{HCl}$ buffer ( $\mathrm{pH} 7.4$ ), $0.45 \mathrm{ml}$ of $0.1 \mathrm{M}$ Tris/ $/ \mathrm{HCl}$ buffer, and 0.05 $\mathrm{ml}$ of $2 \mathrm{mM} \mathrm{FeCl}_{2}$-ascorbic acid solution was added $200 \mathrm{mg}$ of miso, which was then mixed for $10 \mathrm{~s}$ and incubated at $37^{\circ} \mathrm{C}$ for $15 \mathrm{~min}$. To $200 \mu \mathrm{l}$ of the incubated medium was added $20 \mu 1$ of DMPO, which was then mixed for $10 \mathrm{~s}$, then placed in an ESR spectrometry flat cell. The radicals were measured at $50 \mathrm{~s}$ after addition of DMPO under the following conditions: magnetic field, $335 \pm 5 \mathrm{mT}$; response, 0.03 $\mathrm{s}$; sweep time, $0.5 \mathrm{~min}$; amplitude, $2 \times 10^{3}$; modulation amplitude, $0.08 \mathrm{mT}$; and 
power, $8 \mathrm{mV}$. The spin number was calculated by comparing the signal heights of samples with those of known quantities of 2,2,6,6-tetramethyl-4-hydroxylpiperidine-1-oxyl as standard.

Lipid peroxidation. The peroxidation of lipid was induced by adding $2 \mathrm{mM}$ of $\mathrm{FeCl}_{2}$ and ascorbic acid in rat cerebral cortex homogenate as was done in the determination of hydrogen and carbon-centered radicals. After 15-min incubation at $37^{\circ} \mathrm{C}$, TBARS was measured as described by Ohkawa et al. (6) using malondialdehyde as the standard. The fluorescence was analyzed at excitation $515 \mathrm{~nm}$ and emission $532 \mathrm{~nm}$ using tetramethoxy propane standard.

Statistical analysis. Statistical analysis was performed using the Student's $t$-test.

\section{RESULTS}

Table 1 shows (qualitatively) that miso, vitamin $\mathrm{C}$ and vitamin $\mathrm{E}$ scavenged DPPH, hydroxyl and superoxide radicals. Figure 1a and 1c illustrate that at $50 \mathrm{mg} /$ $\mathrm{ml}$ of miso, $100 \%$ and $50 \%$ of the DPPH radicals $\left(3.9 \times 10^{15} \mathrm{spins} / \mathrm{ml}\right)$ and superoxide $\left(6.7 \times 10^{16}\right.$ spins $\left./ \mathrm{ml}\right)$ were quenched, respectively. Whereas, $45 \mathrm{mg} / \mathrm{ml}$ of miso scavenged $92 \%$ of the hydroxyl radicals $\left(7.9 \times 10^{16} \mathrm{spins} / \mathrm{ml}\right)$, as shown in Fig. 1b. ESR hyperfine splitting constants of the hydroxyl radicals are $A_{\mathrm{N}} / G=A_{\mathrm{H}} / G=$ 15.1 , close to that obtained by Buettner (5). The spin adducts of the superoxide show ESR parameters of $A_{\mathrm{N}} / G=14.6$ and $A_{\mathrm{H}} / G=11.4$ and $A_{\gamma} / G=1.2$. Figure 2 depicts the dose-response of the free radical quenching ability of miso at various concentrations. As shown in Fig. 3, $180 \mathrm{mg}$ of miso scavenged about $90 \%$ and $82 \%$ of the hydrogen radicals $\left(1.7 \times 10^{13}\right.$ spins $\left./ \mathrm{ml}\right)$ and carbon-centered radicals $(3.9 \times$ $10^{13}$ spins $/ \mathrm{ml}$ ) which were generated in the homogenate of rat cerebral cortex after the addition of $2 \mathrm{mM}$ each of $\mathrm{FeCl}_{2}$ and ascorbic acid. ESR parameters of the spin adducts are $A_{\mathrm{N}} / G=16.6$ and $A_{\mathrm{H}} / G=22.5$ for DMPO-H and $A_{\mathrm{N}} / G=15.5$ and $A_{\mathrm{H}} / G=$ 23.0 for DMPO-C. Figure 4 shows the inhibitory effect of $10 \mathrm{mg} / \mathrm{ml}$ of miso on TBARS in the homogenate of rat cerebral cortex.

Table 1. Concentration of antioxidants required to quench $50 \%\left(\mathrm{IC}_{50}\right)$ of the free radicals.

\begin{tabular}{lccc}
\hline \multirow{2}{*}{$\begin{array}{c}\text { Antioxidant } / \\
\text { scavenger } \\
(\mu \mathrm{g} / \mathrm{ml})\end{array}$} & $\begin{array}{c}\text { 1,1-Diphenyl-2- } \\
\text { picrylhydrazyl } \\
\left(\times 10^{14} \text { spins } / \mathrm{ml}\right)\end{array}$ & $\begin{array}{c}\text { Hydroxyl } \\
\left(\times 10^{15} \text { spins } / \mathrm{ml}\right)\end{array}$ & $\begin{array}{c}\text { Superoxide } \\
\left(\times 10^{15} \text { spins } / \mathrm{ml}\right)\end{array}$ \\
\cline { 2 - 4 } Vitamin C & 0.80 & 35 & 24 \\
Vitamin E & 2.84 & 37 & $*$ \\
Soybean paste miso & 5,000 & 4,000 & 50,000 \\
\hline
\end{tabular}

Values are means of 5-6 determinations. * Delayed quenching action observed after 6-9 min, in lieu of the usual analytical time of $50 \mathrm{~s}$. 

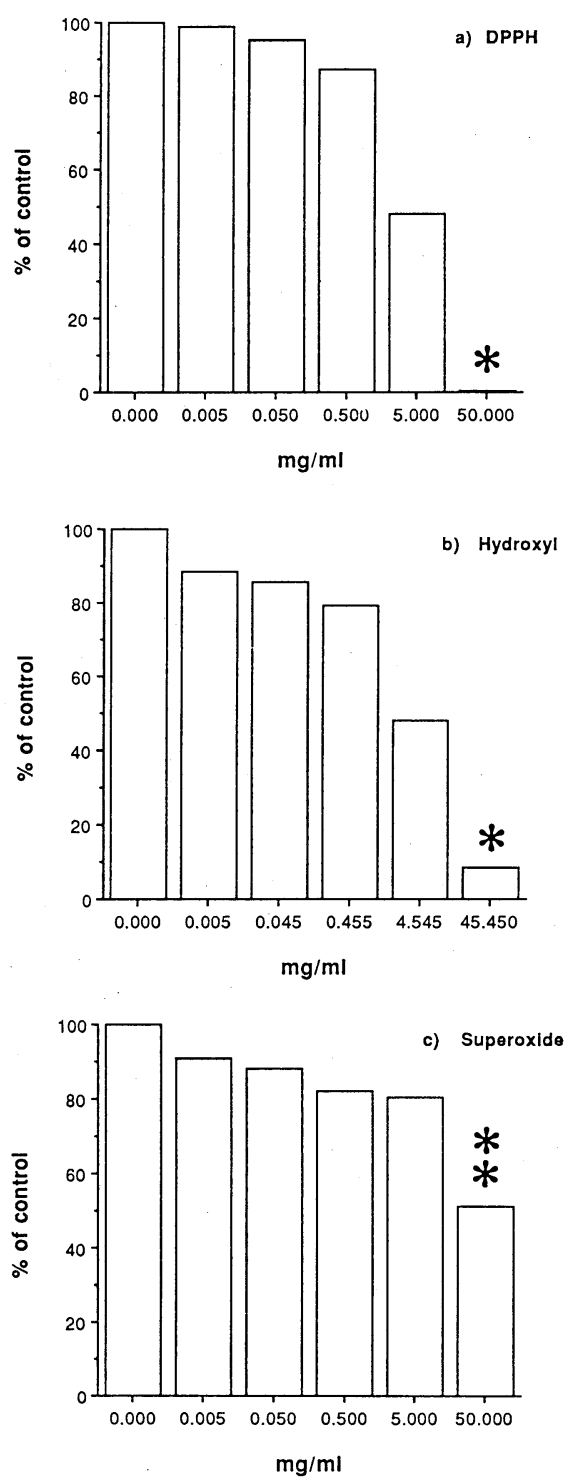

Fig. 1. Dose-response of the scavenging action of soybean paste miso on a) 1,1diphenyl-2-picrylhydrazyl radicals (DPPH), b) hydroxyl radicals, and c) superoxide radicals. The values are the means $(n=6-8) . *_{p}<0.001$ vs. control, $*_{p}<0.025$ vs. control. 

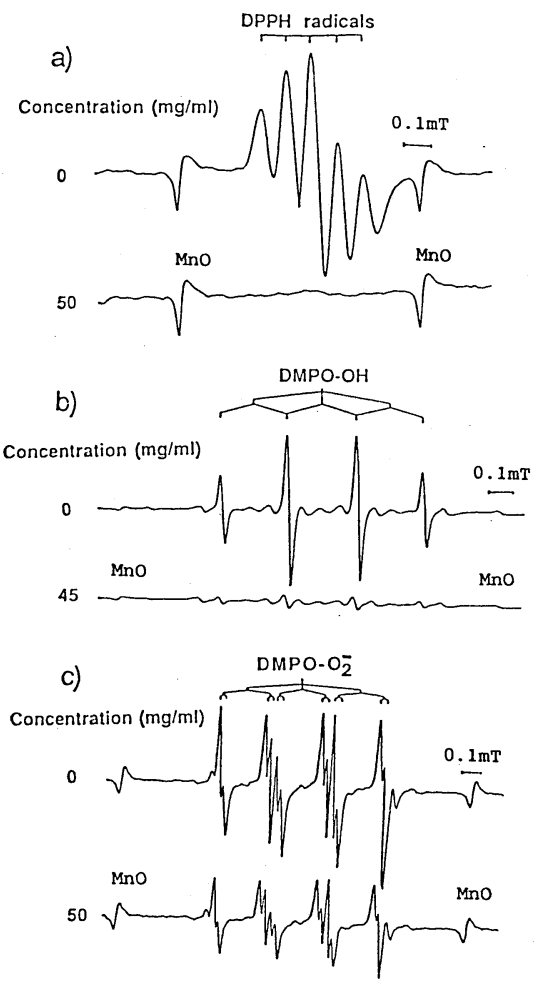

Fig. 2. Effect of soybean paste miso on electron spin resonance spectrum of a) 1,1-diphenyl-2-picrylhydrazyl (DPPH), b) hydroxyl radicals as spin adducts of DMPO-OH with hyperfine splitting constants of $A_{\mathrm{N}}=A_{\mathrm{H}}=15.1$, and c) superoxide radicals as spin adducts of DMPO-O ${ }_{2}^{-}$with hyperfine splitting constants of $A_{\mathrm{N}}=14.6, A_{\mathrm{H}}=11.4$, and $A_{\gamma}=1.2$. Spectra are typical of 6 determinations.

\section{DISCUSSION}

Numerous reports on the nutritional benefits of soybean and soybean paste miso provide an interesting area in which the free radical theory is thought to apply. Soybean, the basic material of miso, has been demonstrated to inhibit mammary tumors in two models of breast cancer in rats using dimethylbenz $[a]$ anthracene (DMBA) and $n$-methyl- $n$-nitrosourea (7) and ionizing radiation (8). Soybean also minimized the carcinogenicity of nitrosamine in mice (9). This anticarcinogenic property has been attributed to protease inhibitors of soybean (10). On one hand, approximately $80 \%$ of soybean paste miso produced in Japan is consumed as miso soup, the consumption of which has been shown by epidemiological studies to be strongly associated with a reduction in gastric cancer mortality in this country (11). Miso itself has been found to lower the incidence of chronic nephritis (12). It has 


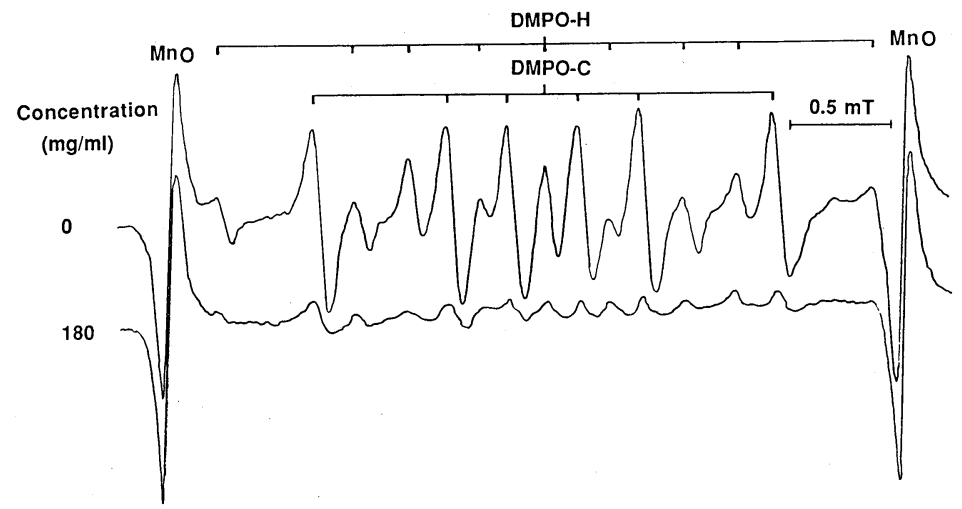

Fig. 3. Scavenging action of soybean paste miso on hydrogen radicals as spin adducts of DMPO and carbon-centered radicals as spin adducts of DMPO generated from rat cerebral cortex homogenate induced with equimolar mixture ( $2 \mathrm{mM}$ ) of $\mathrm{FeCl}_{2}$ and ascorbic acid at $37^{\circ} \mathrm{C}$. Hyperfine splitting constants of DMPO-H are $A_{\mathrm{N}} / G=16.6$ and $A_{\mathrm{H}} / G=22.5$. Hyperfine splitting constants of DMPO-C are $A_{\mathrm{N}} / G=15.5$ and $A_{\mathrm{N}} / G=23.0$.

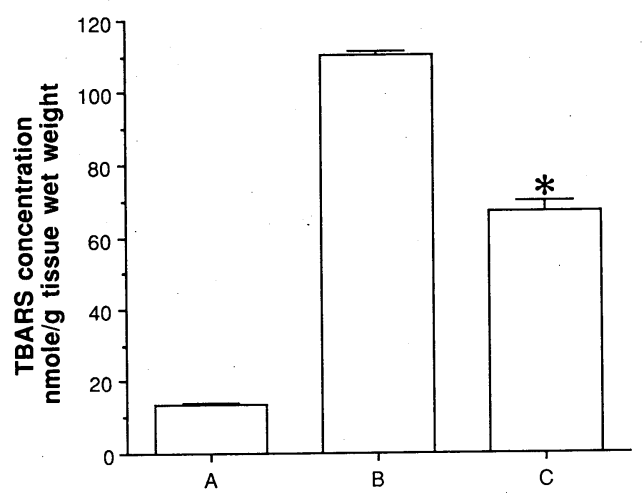

Fig. 4. Thiobarbituric acid-reactive substances (TBARS) in a) rat cerebral cortex homogenate at $37^{\circ} \mathrm{C}$, b) as in (a) but induced with $2 \mathrm{mM}$ each of $\mathrm{FeCl}_{2}$ and ascorbic acid at $37^{\circ} \mathrm{C}, \mathrm{c}$ ) as in (b) but treated with $10 \mathrm{mg} / \mathrm{ml}$ of soybean paste miso. The values are the means $\pm \operatorname{SEM}(n=6) .{ }^{*} \mathrm{C}$ is significantly different from $\mathrm{B} ; \boldsymbol{p}<0.001$.

also been reported to reduce the incidence and to delay the appearance of DMBA-induced mammary adenocarcinomas in rats (13).

Free radicals have been found to be involved in both the initiation and promotion of carcinogenesis. However, antioxidants function as inhibitor at both initiation and promotion/transformation stages of carcinogenesis and protect cells against oxidative damage caused by free radicals (14). Our findings show that miso 
has antioxidant property by scavenging free radicals such as DPPH, hydroxyl, superoxide, hydrogen and carbon-centered radicals. Miso inhibited TBARS formation in rat cerebral cortex, thereby preventing lipid peroxidative damage. $\mathrm{Hy}-$ droxyl and peroxyl radicals and lipid peroxides are known to participate in the initiation and propagation of lipid peroxidation.

The scavenging property of miso may be attributed to soybean, its basic component, which contains a number of known antioxidants such as vitamin $\mathrm{E}$, isoflavones and saponins. Among these, vitamin $\mathrm{E}$ has been shown to correlate with the prevention of cancer (15) and iron-induced epileptiform discharges in rats (16). Vitamin E, a major lipid-soluble chain-breaking antioxidant, has been demonstrated to impart oxidative stability and antioxidant activity in soybean oil (17). Isoflavones from soybeans (18) have been found to have antioxidant action (1). Oral administration of saponins in rats prevented liver injury and hyperlipemia induced by high fat diet containing highly peroxidized corn oil-indicative of saponins' protective action in vivo and in vitro production of lipid peroxides (19). Recently, we found that baker's yeast $S$. cerevisiae scavenged DPPH, hydroxyl and superoxide, quenched hydrogen and carbon-centered radicals and inhibited TBARS in the rat brain homogenate which was induced with $2 \mathrm{mM}$ each of $\mathrm{FeCl}_{2}$ and ascorbic acid (20). Other antioxidants in miso may include fermentation products and other compounds undestroyed by heating in miso soup preparation. All these antioxidants in miso may be responsible for scavenging DPPH, hydroxyl, superoxide, hydrogen and carbon-centered radicals.

L. A. Santiago thanks Sun-O International Inc., Gifu, Japan, for partially financing this study.

\section{REFERENCES}

1) Naim, M., Gestetner, B., Bondi, A., and Birk, Y. (1976): Antioxidative and antihemolytic activities of soybean isoflavones. J. Agric. Food Chem., 24, 1174-1177.

2) Esaki, H., Nohara, Y., Onozaki, H., and Osawa, T. (1990): Antioxidative property of natto. Nippon Shokuhin Kogyo Gakkaishi, 37, 474-477.

3) Gyorgy, P., Murata, K., and Ikehata, H. (1964): Antioxidants isolated from fermented soybeans (tempeh). Nature (Lond.), 203, 870-872.

4) Mcfarlane, B. J., van der Riet, W. B., Bothwell, T. H., Baynes, R. D., Siegenberg, D., Schmidt, U., Tal, A., Taylor, J. R. N., and Mayet, F. (1990): Effect of traditional oriental soy products on iron absorption. Am. J. Clin. Nutr., 51, 873-880.

5) Buettner, G. R. (1987): Spin trapping: ESR parameters of spin adducts. Free Rad. Biol. Med., 3, 259-303.

6) Ohkawa, H., Ohishi, S., and Yagi, K. (1979): Assay for lipid peroxides in animal tissues by thiobarbituric acid reaction. Anal. Biochem., 95, 351-358.

7) Barnes, S., Grubbs, C., Kenneth, D. R., Setchell, and Carlson, J. (1990): Soybean inhibit mammary tumors in models of breast cancer, in Mutagens and Carcinogens in the Diet, New York, pp. 239-253. 
8) Troll, W., Weisner, R., Shellabarger, C. J., Holtzman, S., and Stone, J. P. (1980): Soya bean diet lowers breast tumor incidence in irradiated rats. Carcinogenesis, 1, 469472.

9) Fitzsimons, J. T. R., Orson, N. V., and El-Aaser, A. A. (1989): Effects of soyabean and ascorbic acid on experimental carcinogenesis. Comp. Biochem. Physiol., 93A, 285290.

10) Yavelow, J., Finlay, T. H., Kennedy, A. R., and Troll, W. (1983): Bowman-Birk soybean protease inhibitor as an anticarcinogen. Cancer Res., 43, 2454s-2459s.

11) Hirayama, T. (1982): Relationship of soybean paste soup intake to gastric cancer risk. Nutr. Cancer, 3, 223-233.

12) Hirayama, T. (1987): National burden of disease of urinary organs-An epidemiological consideration. Hinyokika-kiyo, 33, 1550-1555.

13) Baggot, J. E., Ha, T., Vaughn, W. H., Juliana, M. M., Hardin, J. M., and Grubbs, C. J. (1990): Effect of miso (Japanese soybean paste) and $\mathrm{NaCl}$ on DMBA-induced rat mammary tumors. Nutr. Cancer, 14, 103-109.

14) Sun, Y. (1990): Free radicals, antioxidant enzymes, and carcinogenesis. Free Rad. Biol. Med., 8, 583-599.

15) Wattenberg, L. W. (1983): Inhibition of neoplasia by minor dietary constituents. Cancer Res., 43, 2448s-2453s.

16) Rubin, J. J., and Willmore, L. J. (1980): Prevention of iron-induced epileptiform discharges in rats by treatment with antiperoxidants. Exp. Neurol., 67, 472-480.

17) Chow, C. K., and Drapper, H. H. (1974): Oxidative stability and antioxidant activity of the tocopherols in corn and soybean oils. Int. J. Vitam. Nutr. Res., 44, 396-403.

18) Naim, M., Gestetner, B., Kirson, I., Birk, Y., and Bondi, A. (1974): A new isoflavone from soya beans. Phytochemistry, 12, 169-170.

19) Ohminami, H., Kimura, Y., Okuda, H., and Arichi, S. (1984): Effects of soya saponins on liver injury induced by highly peroxidized fats in rats. Planta Med., 50, 440-441.

20) Santiago, L. A., Hiramatsu, M., and Mori, A. (1991): Scavenging action on free radicals and inhibition of lipid peroxidation by baker's yeast. Med. Sci. Res., 19, 867868. 